\title{
Eco-hydrological controls on summertime convective rainfall triggers
}

\section{Authors: Jehn-Yih Juang, Gabriel G. Katul, Amilcare Porporato, Paul C. Stoy, Mario S. Siqueira, Matteo Detto, Hyun-Seok Kim, and Ram Oren}

This is the peer reviewed version of the following article: see citation below, which has been published in final form at https://doi.org/10.1111/j.1365-2486.2007.01315.x. This article may be used for non-commercial purposes in accordance with Wiley Terms and Conditions for SelfArchiving.

Juang, Jehn-Yih, Gabriel G. Katul, Amilcare Porporato, Paul C. Stoy, Mario S. Siqueira, Matteo Detto, Hyun-Seok Kim, and Ram Oren. "Eco-Hydrological Controls on Summertime Convective Rainfall Triggers." Global Change Biology 13, no. 4 (January 10, 2007): 887-896. doi:10.1111/ j.1365-2486.2007.01315.x.

Made available through Montana State University's ScholarWorks scholarworks.montana.edu 


\title{
Eco-hydrological controls on summertime convective rainfall triggers
}

\author{
JEHN-YIH J UAN G*, GABRIEL G. KATUL*†, AMILCARE PORPORATO*†, PAUL C. STOY*, \\ MARIO S. S I QUEIRA*, MATTEO DETTO \\ ${ }^{*}$ Nicholas School of the Environment and Earth Sciences, Duke University, Durham, NC, USA, †Department of Civil and \\ Environmental Engineering, Duke University, Durham, NC, USA, †Dipartimento di Ingegneria Idraulica, Ambientale, \\ Infrastrutture viarie e del Rilevamento, Politecnico di Milano, Italy
}

\begin{abstract}
Triggers of summertime convective rainfall depend on numerous interactions and feedbacks, often compounded by spatial variability in soil moisture and its impacts on vegetation function, vegetation composition, terrain, and all the complex turbulent entrainment processes near the capping inversion. To progress even within the most restricted and idealized framework, many of the governing processes must be simplified and parameterized. In this work, a zeroth-order representation of the dynamical processes that control convective rainfall triggers - namely land surface fluxes of heat and moisture - is proposed and used to develop a semianalytical model to explore how differential sensitivities of various ecosystems to soil moisture states modify convective rainfall triggers. The model is then applied to 4 years (2001-2004) of half-hourly precipitation, soil moisture, environmental, and eddy-covariance surface heat flux data collected at a mixed hardwood forest (HW), a maturing planted loblolly pine forest (PP), and an abandoned old field (OF) experiencing the same climatic and edaphic conditions. We found that the sensitivity of PP to soil moisture deficit enhances the trigger of convective rainfall relative to $\mathrm{HW}$ and $\mathrm{OF}$, with enhancements of about $25 \%$ and $30 \%$ for dry moisture states, and $5 \%$ and $\mathbf{1 5 \%}$ for moist soil moisture states, respectively. We discuss the broader implications of these findings on potential modulations of convective rainfall triggers induced by projected large-scale changes in timberland composition within the Southeastern United States.
\end{abstract}

Keywords: atmospheric mixed-layer, convective rainfall, land cover change, soil moisture

\section{Introduction}

Quantitative analysis of rainfall-runoff relationships may be traced back to 1674, when Pierre Perrault published his seminal monograph De l'origine des fontaines (On the Origin of Springs) on the role of precipitation in sustaining stream flow in the Seine River. About four decades ago, some in the hydrology and climate communities argued that at sufficiently large scales watersheds can modify their own precipitation regimes, thereby marking a fundamental shift in the analysis of the hydrologic cycle (Eagleson, 1986). Nevertheless, hydrological modeling has disproportionately focused on distributions and pathways of water within water- sheds under the assumption that precipitation is an independent forcing term.

Recent studies have suggested that land cover change can significantly affect the Earth's climate from regional to global scales (Chase et al., 2001; Kanae et al., 2002; Liston et al., 2002), with impacts potentially as large as from other anthropogenic factors (e.g. greenhouse gases and aerosols). For example, Baidya Roy et al. (2003) utilized a numerical model to show that land cover change in the United States over the past 300 years significantly altered the climate in July. Focusing on the period from 1910 to 1990, they found that the increase in forested areas in the East Coast region of the United States resulted in lower surface temperature due to higher evapotranspiration (ET). Higher ET provided an important source of moisture thereby slightly enhancing precipitation in the region (Baidya Roy et al., 2003). 
Recent studies further demonstrated that precipitation recycling via transpiration and the control that soil moisture exerts on the partitioning of sensible and latent heat fluxes can contribute to the feedback between the soil moisture state and convective precipitation (Freedman et al., 2001; Findell \& Eltahir, 2003a, b; D'Odorico \& Porporato, 2004; Wu \& Dickinson, 2005).

Present day changes in timberland composition, primarily from mature broadleaf-deciduous forest to pine plantations (Wear \& Greis, 2002), are occurring at spatial scales that may be large enough to influence summertime precipitation regimes, particularly convective precipitation, in the Southeastern United States. Currently, about $60 \%$ of the forested area in this region is covered with hardwood forests. It is projected that by 2040, the total forested area will not be significantly altered but its composition will be 50\% pine (primarily plantation) and 50\% hardwood (Wear \& Greis, 2002). Because convective precipitation is the product of numerous interactions and nonlinear feedbacks among many processes (Eltahir \& Pal, 1996; Findell \& Eltahir, 1999, 2003a), and is further affected by the spatial structure of vegetation and terrain, it has been difficult to assess the effect of such land-cover change on triggers of regional convective rainfall.

To simultaneously address all of the processes that trigger convective rainfall is well beyond the scope of a single study. Instead, we focus on the most elementary dynamical processes that control these triggers; namely land surface fluxes of heat and moisture, which in turn vary with the soil moisture content within the rooting zone. The soil moisture strongly depends on soil-plant hydraulic properties and antecedent soil moisture state (Sperry, 2000; Katul et al., 2003; Bohrer et al., 2005). To progress even within this restricted framework, many of the governing processes must be simplified and parameterized.

The overall objective of this work is to assess how shifts in land-cover type modify convective rainfall triggers. To address this objective, we derive a simplified semianalytical 'zero-dimensional' model that can explicitly propagate the nonlinear effects of vegetation sensitivity of soil moisture to conditions that predispose convective rainfall, while maintaining the key nonlinearities describing these interactions.

The study is organized as follows: we develop a semianalytical solution for the growth of the convective boundary layer as a function of incident shortwave radiation and its partitioning to sensible heat flux, which depends on vegetation type and soil moisture state. Next, we explore the maximum soil moisture state that guarantees sufficient sensible heat flux for the mixed-layer depth to intersect the lifting condensation level, a condition necessary-although not sufficient-for convective rainfall events. We then assess the degree to which this predisposition to convective rainfall events differs among three vegetation types, and how it changes for each type in relation to soil moisture. This assessment is conducted, by applying the model to long-term (from 2001 to 2004) eddy covariance and meteorological data sets from an experimental study site with three adjacent ecosystems that experience the same climatic and edaphic conditions. The study site contains an abandoned old field covered with grass and herbaceous species (OF), a 22-year-old (in 2005) maturing loblolly pine plantation (PP), and an 80- to 100-yearold mature oak-hickory hardwood forest (HW). We limit our analysis to periods spanning from late spring to early fall (May to September, Julian day 121 to day 273), hereafter referred to as 'summertime.' This is roughly the period in which leaf area index (LAI) is at or near its maximum (McCarthy et al., 2006). Removing periods of transient LAI from the analysis allow us to isolate the effects of soil moisture on ecophysiological controls of convective rainfall events during the period when convective rainfall most often occurs. After determining the parameters of the model, we indirectly validate the semianalytical solution using point rainfall measurements. We then briefly discuss the relevance of this work to regional precipitation patterns in the context of projected land-cover changes.

\section{Methods and materials}

\section{Experimental site}

The three adjacent vegetation types $\mathrm{PP}, \mathrm{HW}$, and $\mathrm{OF}$ are located within the Blackwood Division of the Duke Forest near Durham in North Carolina $\left[35^{\circ} 58^{\prime} \mathrm{N}\right.$, $79^{\circ} 05^{\prime} \mathrm{W}, 163 \mathrm{~m}$ above sea level (a.s.l.)] and are part of FLUXNET, an on-going global long-term $\mathrm{CO}_{2}$ flux monitoring initiative (Baldocchi et al., 2001). The soil type is acidic Hapludalf with a clayey loam (Enon silt loam) in the upper $0.3 \mathrm{~m}$, and clay all the way down to bedrock (at $\sim 0.7 \mathrm{~m}$ ). The average saturated soil moisture content within the rooting zone is $0.54 \mathrm{~m}^{3} \mathrm{~m}^{-3}$ (Oren et al., 1998). The dominant rooting system depth at all three stands is about $0.3 \mathrm{~m}$ (Soil Survey of Orange County, North Carolina, 1975).

At each ecosystem, a walkup tower is available to sample long-term environmental and near-surface eddy-covariance flux data. Detailed information about each site and experimental setup are described elsewhere (for OF site, see Novick et al., 2004; for HW and PP sites, see Oren et al., 1998, Stoy et al., 2005, and Pataki \& Oren, 2003). The precipitation, air temperature, relative humidity, radiation components (shortwave, longwave, and net radiation), and rooting-zone soil 


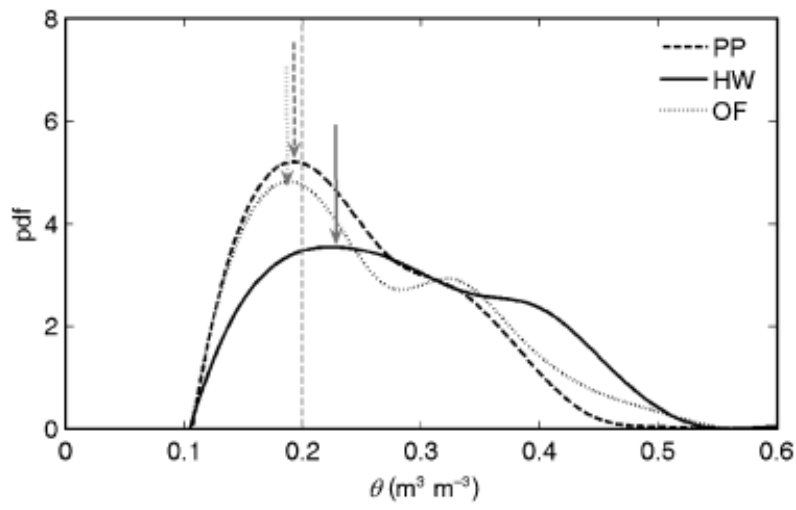

Fig. 1 Probability density function (pdf) of $\theta$ for each ecosystem from 2001 to 2004 during the growing season. The gray arrows indicate the mode of the pdf for each ecosystem.

moisture content are sampled every second and averaged every $30 \mathrm{~min}$. The turbulent sensible and latent heat fluxes are measured using eddy covariance systems with $10 \mathrm{~Hz}$ sampling frequency and $30 \mathrm{~min}$ averaging interval as described elsewhere (Katul et al., 1997; Stoy et al., 2005).

As for the hydrological properties, this region experienced a mild drought event in 2001 and a severe drought event in 2002 during the growing season. The 2001-2004 growing season precipitation nearly covered the wettest and driest states within the past 57 years on record, thereby providing a wide range of soil moisture and air relative humidity conditions. The probability density function (pdf) of $\theta$ for each ecosystem is shown in Fig. 1 for the summer time period. Higher $\theta$ values were more frequently observed at the HW site when compared with the other two ecosystems (Fig. 1). Furthermore, at the PP site, the measured mode $\left(\theta=0.19 \mathrm{~m}^{3} \mathrm{~m}^{-3}\right)$ was below the critical soil moisture content $\left(\theta=0.20 \mathrm{~m}^{3} \mathrm{~m}^{-3}\right)$ known to induce reductions in transpiration with decreasing $\theta$.

\section{Methods}

Assuming the entire mixed-layer depth is a single slab, the temporal dynamics of the mixed-layer height $\left(z_{\mathrm{i}}\right)$ can be derived using the standard budget equation for the mean slab potential temperature $\left(\overline{T_{p}}\right)$ and the encroachment model closure (Stull, 1976, 1988; Garc et al., 2002), given by

$$
\frac{\mathrm{d} z_{\mathrm{i}}}{\mathrm{d} t}=\frac{\overline{w^{\prime} T_{\mathrm{p}_{\mathrm{s}}^{\prime}}^{\prime}}-\overline{w^{\prime} T_{\mathrm{p}_{z_{\mathrm{i}}}^{\prime}}}}{\gamma z_{\mathrm{i}}}
$$

where $\overline{w^{\prime} T_{\mathrm{p}_{\mathrm{s}}}^{\prime}}$ and $\overline{w^{\prime} T_{\mathrm{p}_{z_{\mathrm{i}}}^{\prime}}}$ represent the turbulent sensible heat fluxes above the land surface and at the top of the mixed-layer, respectively; $\gamma$ is the lapse rate of potential temperature just above $z_{\mathrm{i}}$, and $t$ is time. Over-bars represent the time averaging operator, and primed quantities denote turbulent excursions around their time-averaged states. The value of $\gamma$ is often approximated from sounding measurement profiles (Eltahir \& Pal, 1996; Findell \& Eltahir, 1999, 2003a). Here, we determined $\gamma$ using all the summertime morning (0700 LT) sounding data from 2001 to 2004 at Piedmont Triad International Airport (GSO, 36 $05^{\prime} \mathrm{N}, 79^{\circ} 57^{\prime} \mathrm{W}$, $270 \mathrm{~m}$ a.s.l. and $79 \mathrm{~km}$ west of the Duke Forest site). The resulting ensemble-averaged $\gamma=11.6 \times 10^{-3}{ }^{\circ} \mathrm{C} \mathrm{m}^{-1}$ is about $18 \%$ larger than the dry adiabatic lapse rate; this is consistent with other research findings (Haiden, 1997).

For analytical tractability, the sensible heat flux at the top of the mixed-layer $\left(\overline{w^{\prime} T_{p_{z_{i}}^{\prime}}^{\prime}}\right)$ is parameterized using standard encroachment closure schemes (Garratt, 1992)

$$
\overline{w^{\prime} T_{\mathrm{p}_{z_{\mathrm{i}}}^{\prime}}}=-\beta(t) \overline{w^{\prime} T_{\mathrm{p}_{\mathrm{s}}}^{\prime}},
$$

where $\beta$ is a similarity coefficient. Although the value of $\beta$ changes with time of day, several numerical studies and measurements suggest that $\beta$ is between 0.2 and 0.4 (Betts et al., 1992; Kim \& Entekhabi, 1998). Here, we assumed a constant value of $\beta=0.3$ based on findings from Kim \& Entekhabi (1998).

To avoid the use of detailed physiological parameters to model transpiration and evaporation and then model sensible heat flux via energy balance partitioning, we account for the effect of $\theta$ using a dimensionless quantity $\alpha(\theta)$ given by the ratio $H_{\mathrm{s}} / R_{\mathrm{i}}$, where $H_{\mathrm{s}}$ is the surface sensible heat flux $\left(\mathrm{W} \mathrm{m}^{-2}\right)$, given by $H_{\mathrm{s}}=\rho C_{\mathrm{p}} \overline{w^{\prime} T_{\mathrm{p}_{\mathrm{s}}^{\prime}}^{\prime}}$ where $\rho$ is the mean air density, $C_{\mathrm{p}}$ is the specific heat of dry air at constant pressure, and $R_{\mathrm{i}}$ is the incident shortwave radiation $\left(\mathrm{W} \mathrm{m}^{-2}\right)$ at the surface. Thus, the parameter $\alpha$ describes how much of the incident shortwave radiation is converted into sensible heat flux by the ecosystem. Naturally, a moist rooting-zone allows high rates of latent heat flux under high radiation loads, reducing the sensible heat flux, and resulting in a smaller $\alpha(\theta)$ when compared with a drier rooting zone. Furthermore, $\alpha(\theta)$ is not likely to exceed 0.5 even for the driest soil moisture state because net radiation rarely exceeds $70 \%$ of incident shortwave radiation and the half-hourly values of soil heat flux (or heat storage within the canopy volume) are always finite during daytime conditions. This formulation effectively lumps all the physiological, aerodynamic, soil and plant radiative properties, and soil and plant hydraulic properties into one $\alpha(\theta)$ relationship so that the dynamics of the mixed-layer height is approximated as

$$
\frac{\mathrm{d} z_{\mathrm{i}}}{\mathrm{d} t}=\frac{\alpha(\theta)(1+\beta) R_{\mathrm{i}}(t)}{\gamma z_{\mathrm{i}} \rho C_{\mathrm{p}}} .
$$


For analytical tractability, we simply assume that diurnal variations of $R_{\mathrm{i}}$ may be approximated (for cloud-free conditions) by

$$
R_{\mathrm{i}}(t)=R_{\max } \sin \left[\omega\left(t-t_{0}\right)\right],
$$

where $R_{\max }$ is the maximum incident shortwave radiation at a given day of year (and varies with site latitude and elevation), $t$ is in hours, and $\omega=\pi / \tau$, where $\tau$ (hour) is the time span from sunrise $\left(t=t_{0}\right)$ to sunset and also varies with the day of year.

Replacing all these simplifications into Eqn (1) and integrating the outcome from sunrise $\left(t=t_{0}\right)$ to the time when a convective precipitation event (if any) occurs $\left(t=t_{\mathrm{R}}\right)$, yields

$$
\begin{aligned}
& z_{i}\left(t_{\mathrm{R}}\right) \\
& =\sqrt{z_{\mathrm{i}}^{2}\left(t_{0}\right)+2 \frac{\alpha(\theta) \times(1+\beta)}{\gamma \omega \rho C_{\mathrm{p}}}\left\{1-\cos \left[\omega\left(t_{\mathrm{R}}-t_{0}\right)\right]\right\} R_{\max }},
\end{aligned}
$$

where $z_{\mathrm{i}}\left(t_{0}\right)$ is the antecedent depth of the stable boundary layer just before sunrise and can be estimated from dimensional analysis (Zilitinkevich, 1972). Note that Eqn (5) suggests that the growth of $z_{\mathrm{i}}(t)$ can be analytically determined from the soil moisture content through the value of $\alpha(\theta)$, which is primarily (but not exclusively) controlled by the sensitivity of the latent heat flux to soil moisture stress.

Also, for analytical tractability, we assume that the intersection of $z_{i}$ with the lifting condensation level $\left(H_{\mathrm{LCL}}\right)$ is a necessary condition for convective rainfall triggering. The quantity $H_{\mathrm{LCL}}$ varies with the surface mixing ratio $(r(t))$, mean air temperature $\left(T_{\mathrm{a}}(t)\right)$, and surface pressure $\left(P_{\mathrm{s}}\right)$ using

$$
H_{\mathrm{LCL}}=\frac{R T_{\mathrm{a}}}{M_{\mathrm{a}} g} \log \left(\frac{P_{\mathrm{s}}}{P_{\mathrm{LCL}}}\right),
$$

where $R$ is the universal gas constant $\left(=8.314 \mathrm{~J} \mathrm{~mol}^{-1} \mathrm{~K}^{-1}\right)$, $M_{\mathrm{a}}$ is the molecular weight of the air $\left(\sim 29 \mathrm{~g} \mathrm{~mol}^{-1}\right), P_{\mathrm{s}}$ $(\mathrm{kPa})$ is the local atmospheric pressure at the surface, and $P_{\mathrm{LCL}}(\mathrm{kPa})$ is the atmospheric pressure at $H_{\mathrm{LCL}}$. The value of $P_{\mathrm{LCL}}$ can be approximately determined from a hydrostatic assumption using

$$
P_{\mathrm{LCL}}=P_{\mathrm{s}}\left(\frac{T_{\mathrm{LCL}}}{T_{\mathrm{a}}}\right)^{3.5},
$$

where $T_{\mathrm{LCL}}(K)$ is the saturation point temperature at $H_{\mathrm{LCL}}$ and can be derived from the Clausius-Clapeyron equation given by (Stull, 1988)

$$
T_{\mathrm{LCL}}=\frac{2840}{3.5 \ln \left(T_{\mathrm{a}}\right)-\ln \left(\frac{P_{\mathrm{s}} r}{0.622+r}-7.108\right)}+55,
$$

where $r$ can be calculated from the near-surface relative humidity $\mathrm{RH}$, and the parameter 3.5 is given from the inverse of the Poisson constant.
It directly follows from Eqn (5) that for a specified atmospheric humidity and air temperature states, convective rainfall is primarily 'triggered' when the rooting-zone soil moisture leads to an $\alpha$ exceeding

$$
\alpha(\theta) \geq \frac{\gamma \omega \rho C_{\mathrm{p}}\left\{\left[H_{\mathrm{LCL}}\left(r, T_{\mathrm{a}}, P_{\mathrm{s}}\right)\right]^{2}-\left[z_{i}\left(t_{0}\right)\right]^{2}\right\}}{2(1+\beta)\left\{1-\cos \left[\omega\left(t_{\mathrm{R}}-t_{0}\right)\right]\right\} R_{\max }} .
$$

Equation (9) defines the minimum $\alpha$ that is needed to ensure that sufficient sensible heat flux is available to increase $z_{\mathrm{i}}$ up to $H_{\mathrm{LCL}}$. Naturally, this condition predisposes, but does not necessarily lead to, convective rainfall. When air parcels reach $H_{\mathrm{LCL}}$, condensation forms in regions of negatively buoyant 'overshoots of mixed-layer thermals' (Stull, 1988). These thermals penetrate the capping inversion at the top of $z_{\mathrm{i}}$. If the overshoot is sufficiently strong to continue lifting the condensing air parcel, latent heat is released and its potential temperature becomes sufficiently warmer than the surrounding environment and it becomes positively buoyant. The height at which a cloudy air parcel becomes positively buoyant defines the 'level of free convection,' LFC. This parcel continues to buoyantly rise until it eventually becomes cooler than its surrounding environment at which point the 'limit of convective' rise, LOC, is attained. Any residual inertia in the rising parcel might propel it to continue rising further eventually stopping at the cloud top (Stull, 1988; Emanuel et al., 1994). Several measures of potential energies are available to quantify the cloud thickness, often defined between LFC and LOC, such as convective available potential energy (CAPE) and evaporative available potential energy (EAPE). Once clouds develop, condensation nuclei allow rapid growth of water droplet. When these water droplets reach sufficient size to precipitate and repenetrate the unsaturated air below the cloud base without completely evaporating before reaching the ground surface, rainfall at the surface occurs. Roughly, after $z_{\mathrm{i}}$ intersects $H_{\mathrm{LCL}}$, this entire process leading to precipitation detection at the ground may vary from minutes up to $2 \mathrm{~h}$ (Stull, 1988). Thus, Eqn (9) must be viewed as a necessary - but not sufficient condition for convective rainfall events.

The presence of vegetation may impact the estimation of the lifting condensation level $H_{\mathrm{LCL}}(t)$ because the measured air temperature $T_{\mathrm{a}}(t)$ and mixing ratio $r(t)$ within or near the canopy sublayer are known to differ among vegetation types. To assess the potential impact of vegetation types on $H_{\mathrm{LCL}}$ at the study site, and thus on our study, we compared $H_{\mathrm{LCL}}$ using the near surface measured $T_{\mathrm{a}}(t)$ and $r(t)$ collected at $\mathrm{OF}, \mathrm{HW}$, and PP and found that $H_{\mathrm{LCL}}$ is robust to the underlying land-cover surface at this site (Fig. 2). This finding is not entirely surprising because the temporal dynamics of $T_{\mathrm{a}}(t)$ and 


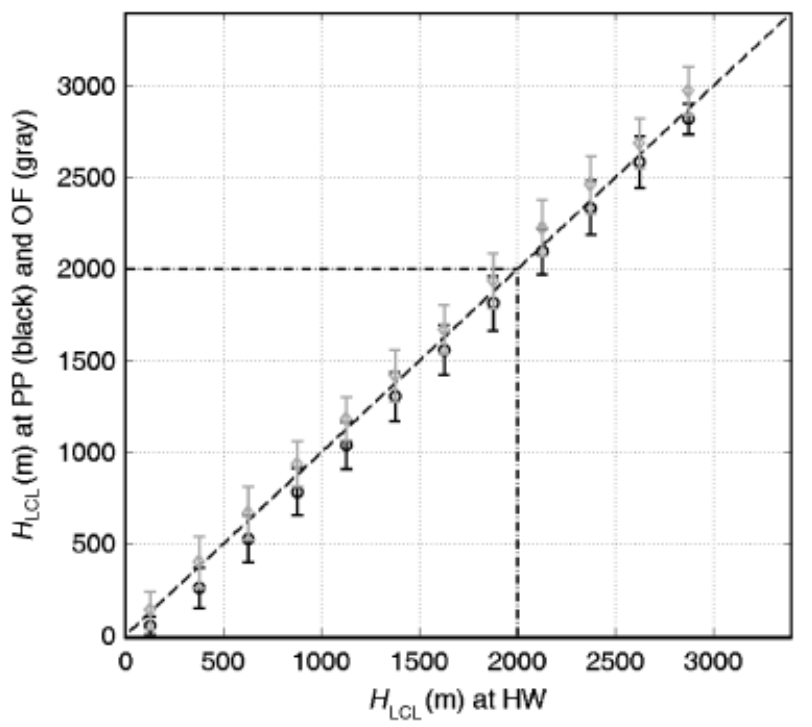

Fig. 2 Lifting condensation level $\left(H_{\mathrm{LCL}}\right)$ derived using $r(t)$ and $T(t)$ measured at PP (error bars in black) and OF (error bars in gray) when compared with those measured from the HW ecosystem (the dominant land cover type in a $10 \mathrm{~km} \times 10 \mathrm{~km}$ region around the site). The dash-dot lines at $2000 \mathrm{~m}$ represent the maximum mixed-layer depth in this region. The dots represent the ensemble average of all half-hourly runs and the vertical bar is $1 \mathrm{SD}$ around the ensemble average.

$r(t)$ are often much larger than their spatial variability across these three ecosystems. Hence, in a first-order analysis, it is reasonable to assume that $H_{\mathrm{LCL}}(t)$ is approximately the same at all three ecosystems.

\section{Results and discussion}

We now focus on the impact of vegetation on triggers of convective rainfall and present indirect but independent validation of the proposed semianalytical model using point rainfall measurements.

\section{Soil moisture and vegetation control on partitioning of surface fluxes}

Figure 3 shows how $\theta$, measured at each of the three ecosystems, affect the value of $\alpha$. Here, we discuss the convective rainfall disposition mechanism for two different soil moisture regimes.

(1) Regime $1, \partial \alpha / \partial \theta \approx 0$ :

This regime exists for relatively moist soil conditions at all three sites; however, the onset of this regime differs among the three sites. For the forested ecosystems here, the onset of this regime appears to be $\theta>0.20 \mathrm{~m}^{3} \mathrm{~m}^{-3}$. This onset is consistent with the threshold soil moisture known to regulate stomatal conduc- tance (Oren et al., 1998; Oren \& Pataki, 2001). For the OF site, the onset of this regime occurs at a much higher soil moisture state $\left(\theta>0.20 \mathrm{~m}^{3} \mathrm{~m}^{-3}\right)$ suggesting that soil moisture controls on $\alpha$ are active over a much broader range of conditions during the growing season (see Fig. 1 for the mode of $\theta$ ).

(2) Regime 2, $\partial \alpha / \partial \theta<0$ :

In this regime, $\alpha$ increases with decreasing $\theta$. As earlier stated, this increase reflects a number of processes, including soil moisture controls on transpiration, soil evaporation, and soil heat flux. The three ecosystems differ in both magnitude of $|\partial \alpha / \partial \theta|$ and its nonzero onset. In light of the pdfs in Fig. 1, we emphasize that this regime occurs by far more frequently during summertime when compared with regime 1 at all three sites. For the forested ecosystems, we find that $|\partial \alpha / \partial \theta|$ for HW is much smaller than PP, suggesting that the convective rainfall dispositions at HW are the least sensitive to variations in soil moisture when compared with OF and PP. For PP, $|\partial \alpha / \partial \theta|$ rapidly increases when $\theta<0.18$, even exceeding its OF counterpart for these dry states. When $\theta$ decreases to the driest condition observed in the data record (i.e. $\theta=0.13 \mathrm{~m}^{3} \mathrm{~m}^{-3}$, Fig. 1), the value of $\alpha$ increases to $\sim 0.33$ at $\mathrm{PP}, \sim 0.29$ at $\mathrm{OF}$, and $\sim 0.21$ at HW. Hence, the highest $\alpha$ was, surprisingly, not at OF but at PP.

Interestingly, the comparison of $\alpha$ among different vegetation types for regime 1 suggests that $\alpha(=0.21)$ at PP remains significantly larger than the other two vegetation types ( $\alpha=0.15$ for HW and $\alpha=0.16$ for OF). Given that these three vegetation types experience the same incident shortwave radiation and precipitation, we explored potential explanations for this pattern in observed minimum $\alpha$ using the corresponding frequency distributions of the energy budget components (net radiation $R_{\mathrm{n}}$, sensible heat flux $H_{\mathrm{s}}$, and latent heat flux $L E$ ), and the residuals (the difference between $R_{\mathrm{n}}$ and $H_{\mathrm{s}}+L E$ ). We restrict this analysis to near convective conditions over the entire 4-year summertime record because they are more pertinent to triggers of convective rainfall (Fig. 4). Here, free convective conditions prevail when the atmospheric stability parameter $(z / L)$ satisfies the condition $-z / L \geq 5$ (Juang et al., 2007), where $z=z_{\mathrm{i}} / 2$, and $L$ is the Obukhov length, which is derived from the near surface friction velocity $\left(u_{*}\right), \overline{w^{\prime} T_{\mathrm{p}_{s}}^{\prime}}$ and $T_{\mathrm{a}}$.

While incident shortwave radiation is identical in all three ecosystems, $R_{\mathrm{n}}$ is not necessarily identical given differences among the vegetation types in albedo, surface emissivity, and skin temperature. This difference is most evident in Fig. 4, which presents the modes of measured $R_{\mathrm{n}}$ distributions across the entire summertime period for the 4-year record. OF has higher albedo and skin temperature and yields the smallest $R_{\mathrm{n}}$ mode, 

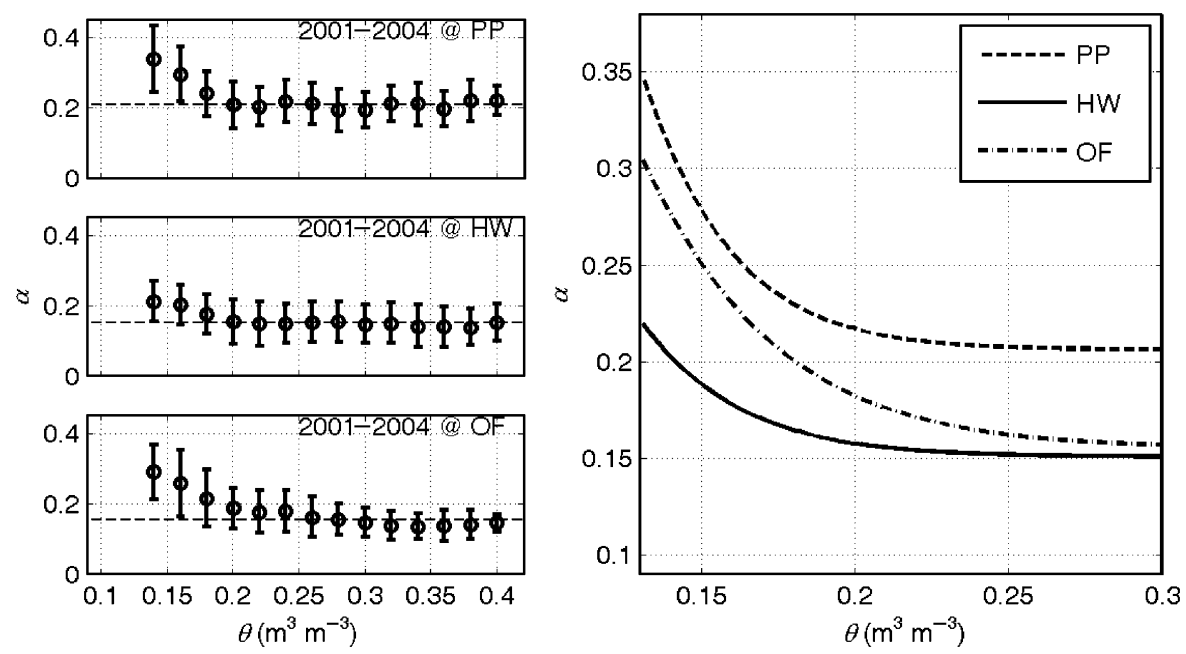

Fig. 3 Relationship between measured local $\theta$ and measured ensemble averaged $\alpha\left(H_{\mathrm{s}}\right.$ normalized by $\left.R_{\mathrm{i}}\right)$ for each ecosystem (left panel). The regression curves to these data are also shown for comparisons (right panel).

followed in turn by PP, and HW. Interestingly, for moist soil conditions, the modes in LE are comparable suggesting that evaporation, in addition to transpiration, should be significant at OF given the large differences in LAI. The frequency distribution of the combined storage and soil heat fluxes (i.e. the residuals of $\left.R_{\mathrm{n}}-\left(H_{\mathrm{S}}+\mathrm{LE}\right)\right)$ show the largest residual for HW followed in turn by OF and PP. At HW, the storage flux can be significantly large due to the large canopy volume (maximum canopy height $=35 \mathrm{~m}$ ); at the OF site, the soil heat flux is significant in the energy partitioning (at least when compared with PP). These two factors may account for higher $H_{\mathrm{s}}$ at PP when compared with HW and OF under moist soil conditions (see Fig. 4). When the soil is dry, the modes of the LE fluxes diverge, but the modes of the combined storage and soil heat flux distributions retain their relative importance. This analysis clearly demonstrates that the role of soil heat flux, canopy heat storage, and soil evaporation must be considered when the mixed-layer height is modeled based on the energy budget.

Next, we illustrate the potential impact of the observed differences in $\alpha(\theta)$ among the three vegetation types on forecasting triggers for convective rainfall events. Before doing so, however, we test whether the sinusoidal approximation for the incidental shortwave radiation [Eqn (4)] is reasonable here. Figure 5 suggests that this approximation is sufficiently accurate for clear sky conditions up to the formation of clouds. We also compared the ratio of maximum $z_{\mathrm{i}}$ derived at PP and OF with the maximum $z_{\mathrm{i}}$ computed at HW (the dominant species in the $10 \mathrm{~km} \times 10 \mathrm{~km}$ area around the site) as a function of $\theta$. Based on the model calculations, PP enhances convective rainfall triggers over $\mathrm{HW}$ by $\sim 17 \%$ when soils are moist and $\sim 25 \%$ during conditions in which the soil reaches its driest state (Fig. 6). In contrast, when $\theta>0.30 \mathrm{~m}^{3} \mathrm{~m}^{-3}$, OF and HW generate a similar enhancement of convective rainfall triggers; however as the soil dries, the enhancement of convective rainfall triggers by $\mathrm{OF}$ increases relative to that by $\mathrm{HW}$, reaching an $18 \%$ greater trigger potential at $\theta=0.13 \mathrm{~m}^{3} \mathrm{~m}^{-3}$.

\section{Testing the model using point rainfall measurements}

Although it is not possible to directly test the model, some indirect tests can be conducted to assess whether the semianalytical model captures the 'canonical attributes' of convective rainfall triggers. However, before presenting these tests, it is necessary to discuss the spatial 'scale' of convective rainfall triggers in the context of this experiment.

Convective rainfall cells extend a few kilometers horizontally, and the land-surface 'footprint' impacting this trigger is at least $10 \mathrm{~km} \times 10 \mathrm{~km}$. Using a supervised land cover classification scheme on a multispectral image (IKONOS satellite, Space Imaging, Thornton, CO, USA) collected on September 19 of 2004, we determined that PP-, HW-, OF-type ecosystems and 'other' land covers (mainly residential area and roads) cover $33.3 \%, 41.6 \%, 16.8 \%$, and $8.3 \%$ of the $10 \mathrm{~km} \times 10 \mathrm{~km}$ area surrounding the study site, respectively (Juang et al., 2007). We reassigned the 'other' land cover types to OF. Using the measured sensible heat flux at OF, PP, and HW and applying an area-weighted average, we determined the overall sensible heat flux responsible for mixed-layer growth at this spatial scale (Juang et al., 2007). Similarly, we computed the area-averaged soil 

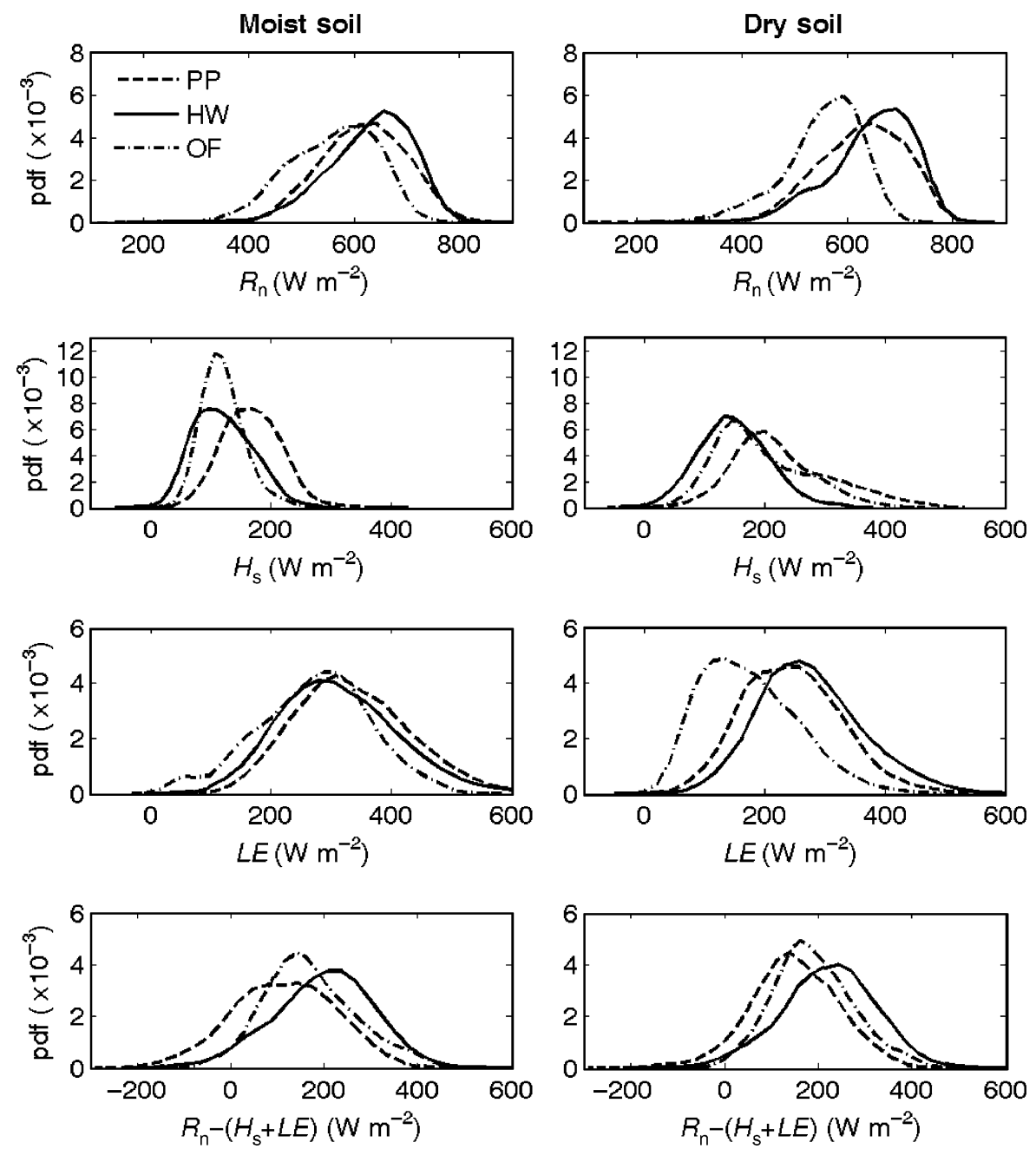

Fig. 4 Frequency distribution of measured net radiation $\left(R_{\mathrm{n}}\right)$, sensible heat flux $\left(H_{\mathrm{s}}\right)$, latent heat flux (LE), and the residuals at PP, HW, and $O F$ for both moist $\left(\theta \geq 0.2 \mathrm{~m}^{3} \mathrm{~m}^{-3}\right)$ and dry soil $\left(\theta<0.2 \mathrm{~m}^{3} \mathrm{~m}^{-3}\right)$ conditions. The data represent midday (1100-1400 LT) condition from day 121 to day 273 in $2001-2004$.

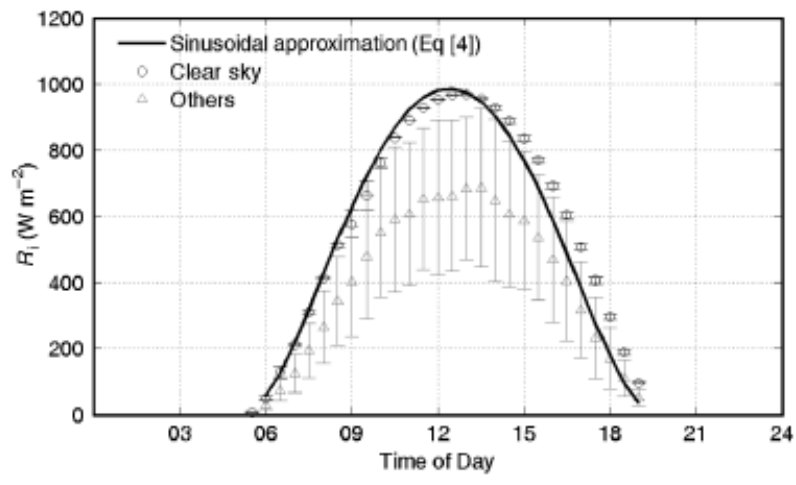

Fig. 5 Temporal variation of incident shortwave radiation $\left(R_{\mathrm{i}}\right)$ from the measurements and the sinusoidal approximation [Eqn (4)]. The condition 'others' refers to days that are not cloud-free.

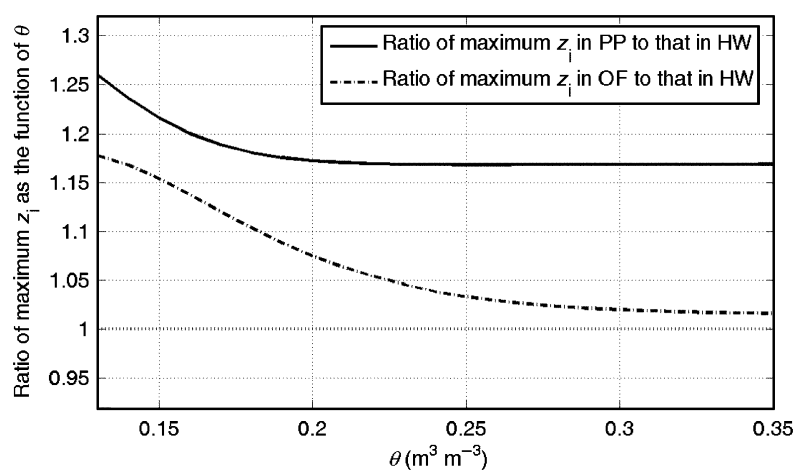

Fig. 6 Modeled ratio of maximum $z_{\mathrm{i}}$ at PP (dashed line) and maximum $z_{\mathrm{i}}$ at $\mathrm{OF}$ (solid line) to the maximum $z_{\mathrm{i}}$ at $\mathrm{HW}$ as a function of local soil moisture content $(\theta)$. 


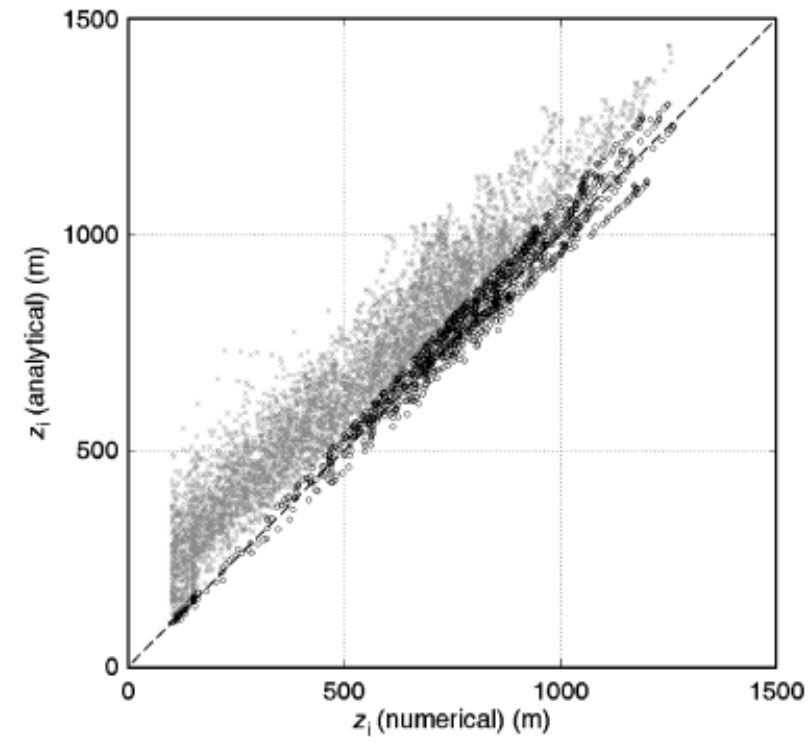

Fig. 7 A comparison of $z_{i}$ derived with the analytical expression and the numerical method. The gray points include all runs while the dark open circles are for clear-sky conditions. The 1:1 line is also shown for reference.

moisture content, area-averaged $\alpha$, and $H_{\mathrm{LCL}}$ (although we showed earlier the latter does not vary spatially). Using the time series of the area-averaged sensible heat flux, we numerically solved for $z_{i}$ using Eqn (1) and compared these numerical results with the semianalytical model in Eqn (5) for all the growing season days within the 4-year record. The semianalytical model was forced with the area-averaged $\theta$ and assumes a sinusoidal $R_{\mathrm{s}}$. This comparison, shown in Fig. 7, suggests that $z_{i}$ estimated from the semianalytical expression overestimates the numerically derived $z_{i}$ by about $350 \mathrm{~m}$. This overestimation is expected because Eqn (5) assumes clear sky conditions while the numerical model in Eqn (1) was forced by the measured $H_{\mathrm{s}}$ thereby accounting for cloud effects on surface heating. When only clear sky days are used in this comparison, the agreement between the semianalytical and the numerical models is remarkably good $( \pm 8 \%)$. The relationship shown in Fig. 7 suggests that Eqn (5) can reasonably describe the dynamics in $z_{\mathrm{i}}$ for clear-sky conditions. Note that in Eqn (5), when all the environmental factors $\left[R_{\max }, \rho, \gamma\right.$, and $\left.z_{\mathrm{i}}\left(t_{0}\right)\right]$ are specified, the value of $z_{\mathrm{i}}\left(t_{\mathrm{R}}\right)$ is strictly a function of $\alpha$ and $t$. Hence, the errors incurred in determining the spatially averaged $\theta$ propagate to $z_{\mathrm{i}}\left(t_{\mathrm{R}}\right)$ in Eqn (5).

We also compare how well the semianalytical and numerical models predict $t_{\mathrm{R}}$, namely the timing of convective rainfall detected by the tipping bucket gauge (e.g. Fig. 8). We find that both models reproduced $t_{\mathrm{R}}$ reasonably well. In the computations of $t_{R}, H_{\mathrm{LCL}}$ was

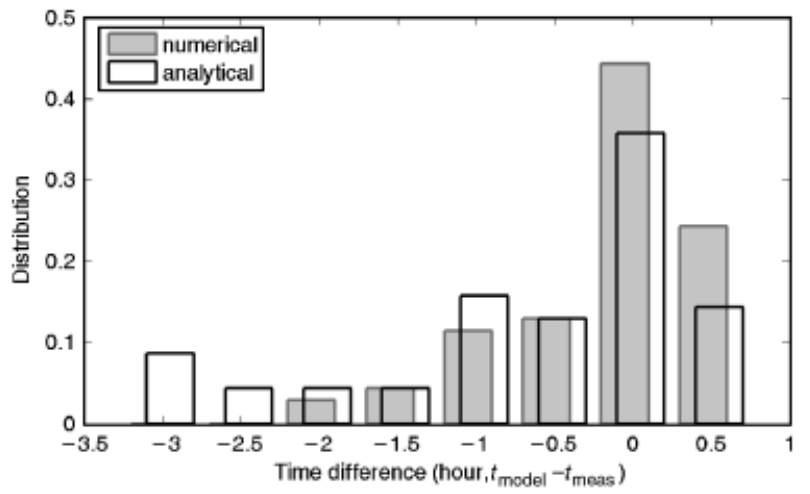

Fig. 8 Frequency distribution of the timing error between tipping bucket precipitation measured with rain gauges and modeled (i.e., when $z_{\mathrm{i}}=H_{\mathrm{LCL}}$ ) using the analytical and numerical approaches.

forced by the area-averaged $r(t)$ and $T_{\mathrm{a}}(t)$. This agreement in $t_{\mathrm{R}}$ supports the argument that under clear sky conditions both - analytical and numerical models can predict well the convective rainfall triggers. However, the semianalytical expression produces an error distribution in the timing that has a heavier tail in the negative region (Fig. 8). By assuming cloud-free conditions in the semianalytical expression, greater mixedlayer height is induced with earlier intersection between $z_{\mathrm{i}}$ and $H_{\mathrm{LCL}}$. The mode of the 'timing error' histogram is $-0.60 \mathrm{~h}$ for the semianalytical model and $-0.18 \mathrm{~h}$ for the numerical model. Noting that the tipping bucket gauge is a point rainfall measure summed every $0.5 \mathrm{~h}$, and noting that convective rainfall does not occur instantly when the lifting condensation level intersects the boundary layer depth, a $-0.6 \mathrm{~h}$ timing error should not be a primary cause for concern.

\section{Conclusions and broader impacts}

This study demonstrated that for clear sky conditions, a simple semianalytical expression that links the soil moisture state within the root zone to the mixed-layer depth has remarkable skills in predicting the timing of convective precipitation when other necessary conditions cause it to occur. While the analytical model proposed here makes several assumptions about the convective boundary depth dynamics, recent advances in ceilometers may offer a platform where this depth can be routinely measured in the near future (Emeis et al., 2004). The broader impact of this work lies in its relevance to assessing how shifts in land cover types might impact summertime convective rainfall. For example, over the past half century, the timberland area in the SE experienced little fluctuation $(\sim \pm 3.1 \%$ with a 
minimum of $793000 \mathrm{~km}^{2}$ in 1989 and a maximum of $845000 \mathrm{~km}^{2}$ in 1956) (Juang et al., 2007; Wear \& Greis, 2002); however, the composition of the timberland area has been significantly changing. The proportion of planted pine forests to the total timberland area in the SE region has dramatically increased from under $1.0 \%$ in the early 1950 s to about $16.9 \%$ in 1999 . Furthermore, based on economic and land-use projections, the proportions of planted pine is expected to increase up to 30.5\% by year 2040 (Wear \& Greis, 2002). Such dramatic land cover change may significantly alter the pattern of summertime convective precipitation. Our analysis suggests that increasing coverage of pine plantation may lead to increased convective rainfall trigger activity during the summertime. At the regional scale, this may also mean that the pines, the most drought sensitive among the forest types, may produce conditions predisposing the atmosphere to produce rains, thus reducing, on average, the effect of droughts.

\section{Acknowledgments}

This study was supported, in part, by US Department of Energy (DOE) through the Office of Biological and Environmental Research (BER), Terrestrial Carbon Processes (TCP), and the National Institute of Global Environmental Change (NIGEC) Southeastern Regional Center (SERC) at the University of Alabama (Cooperative Agreement No. DE-FC02-03ER63613), and by the National Science Foundation (NSF-EAR and NSF-DMS).

\section{References}

Baidya Roy S, Hurtt GC, Weaver CP, Pacala SW (2003) Impact of historical land cover change on the July climate of the United States. Journal of Geophysical Research-Atmospheres, 108, 4793-4806.

Baldocchi DD, Falge E, Gu L et al. (2001) FLUXNET: a new tool to study the temporal and spatial variability of ecosystemscale carbon dioxide, water vapor and energy flux densities. Bulletin of the American Meteorological Society, 82, 2415-2435.

Betts AK, Desjardins RL, MacPherson J (1992) Budget analysis of the boundary layer grid flights during FIFE 1987. Journal of Geophysical Research-Atmospheres, 97, 18533-18546.

Bohrer G, Mourad H, Laursen TA, Drewry D, Avissar R, Poggi D, Oren R, Katul GG (2005) Finite element tree crown hydrodynamics model $(\mathrm{FETCH})$ using porous media flow within branching elements: a new representation of tree hydrodynamics. Water Resources Research, 41, W11404.

Chase TNS, Kittel TGF, Zhao M et al. (2001) Relative climatic effects of landcover change and elevated carbon dioxide combined with aerosols: a comparison of model results and observations. Journal of Geophysical Research-Atmospheres, 106, 31685-31692.

D'Odorico P, Porporato A (2004) Preferential states in soil moisture and climate dynamics. Proceedings of the National Academy of Sciences of the United States of America, 101, 8848-8851.
Eagleson PS (1986) The emergence of global-scale hydrology. Water Resources Research, 22, 6-14.

Eltahir EAB, Pal JS (1996) Relationship between surface conditions and subsequent rainfall in convective storms. Journal of Geophysical Research-Atmospheres, 101, 26237-26246.

Emanuel LA, Neelin JD, Bretherton CS (1994) On large-scale circulations in convecting atmospheres. Quarterly Journal of the Royal Meteorological Society, 120 (Part B), 1111-1143.

Emeis S, Munkel C, Vogt S, Muller WJ, Schafer K (2004) Atmospheric boundary-layer structure from simultaneous SODAR, RASS, and ceilometer measurements. Atmospheric Environment, 38, 273-286.

Findell KL, Eltahir EAB (1999) Analysis of the pathways relating soil moisture and subsequent rainfall in Illinois. Journal of Geophysical Research-Atmospheres, 104, 31565-31574.

Findell KL, Eltahir EAB (2003a) Atmospheric controls on soil moisture-boundary layer interactions. Part I: framework development. Journal of Hydrometeorology, 4, 552-569.

Findell KL, Eltahir EAB (2003b) Atmospheric controls on soil moisture-boundary layer interactions. Part II: feedbacks within the continental United States. Journal of Hydrometeorology, 4, 570-583.

Freedman JM, Fitzjarrald DR, Moore KE, Sakai RK (2001) Boundary layer clouds and vegetation - atmosphere feedbacks. Journal of Climate, 14, 180-197.

Garc JA, Cancillo ML, Cano JL (2002) A case study of the morning evolution of the convective boundary layer depth. Journal of Applied Meteorology, 2002, 1053-1059.

Garratt JR (1992) The Atmospheric Boundary Layer. Cambridge University Press, Cambridge, UK.

Haiden T (1997) An analytical study of cumulus onset. Quarterly Journal of the Royal Meteorological Society, 123 (Part A), 1945-1960.

Juang J-Y, Porporato A, Stoy PC et al. (2007) Hydrologic and atmospheric controls on initiation of convective precipitation events. Water Resources Research, in press.

Kanae S, Oki T, Musiake K (2002) Impact of deforestation on regional precipitation over the Indochina peninsula. Journal of Hydrometeorology, 2, 51-70.

Katul G, Leuning R, Oren R (2003) Relationship between plant hydraulic and biochemical properties derived from a steadystate coupled water and carbon transport model. Plant, Cell and Environment, 26, 339-350.

Katul GG, Oren R, Ellsworth DS, Hsieh C, Phillips N, Lewin K (1997) A Lagrangian dispersion model for predicting $\mathrm{CO}_{2}$ sources, sinks, and fluxes in a uniform loblolly pine (Pinus taeda L.) stand. Journal of Geophysical Research-Atmospheres, 102, 9309-9321.

Kim CP, Entekhabi D (1998) Feedbacks in the land-surface and mixed-layer energy budgets. Boundary-Layer Meteorology, 88, $1-21$.

Liston GE, McFadden JP, Sturm M, Pielke Sr RA (2002) Modelled changes in arctic tundra snow, energy and moisture fluxes due to increased shrubs. Global Change Biology, 8, $17-34$.

McCarthy HR, Oren R, Finzi AC et al. (2006) Canopy leaf area constrains $\left[\mathrm{CO}_{2}\right]$-induced enhancement of productivity and partitioning among aboveground carbon pools. Proceedings of 
the National Academy of Sciences of the United States of America, 103, 19356-19361.

Novick KA, Stoy PC, Katul GG, Ellsworth DS, Siqueira MB, Juanq J, Oren R (2004) Carbon dioxide and water vapor exchange in a warm temperate grassland. Oecologia, 138, 259-274.

Oren R, Ewers B, Todd P, Phillips N, Katul G (1998) Water balance delineates the soil layer in which moisture affects canopy conductance. Ecological Applications, 8, 990-1002.

Oren R, Pataki DE (2001) Transpiration in response to variation in microclimate and soil moisture in southeastern deciduous forests. Oecologia, 127, 549-559.

Pataki DE, Oren R (2003) Species differences in stomatal control of water loss at the canopy scale in a mature bottomland deciduous forest. Advances in Water Resources, 26, 1267-1278.

Sperry JS (2000) Hydraulic constraints on plant gas exchange. Agricultural and Forest Meteorology, 104, 13-23.

Stoy P, Katul GG, Siqueira MBS, Juang JY, McCarthy HR, Kim HS, Oischi C, Oren R (2005) Variability in net ecosystem exchange from hourly to inter-annual time scales at adjacent pine and hardwood forests: a wavelet analysis. Tree Physiology, 25, 887-902.

Stull RB (1976) The energetics of entrainment across a density interface. Journal of the Atmospheric Sciences, 33, 1260-1267.

Stull RB (1988) An Introduction to Boundary Layer Meteorology. Kluwer Academic Publishers Group, Dordrecht, the Netherlands.

Wear DN, Greis JG (2002) Southern forest resource assessment. Gen. Tech. Rep. SRS-53. US Department of Agriculture, Forest Service, Southern Research Station, Asheville, NC, 635 pp.

Wu W, Dickinson RE (2005) Warm-season rainfall variability over the US Great plains and its correlation with evapotranspiration in a climate simulation. Geophysical Research Letters, 32, L17402.

Zilitinkevich SS (1972) On the determination of the height of the Ekman boundary layer. Boundary-Layer Meteorology, 3, 141-145. 